Short communication

\title{
A new emaravirus discovered in Pistacia from Turkey
}

\author{
Nihal Buzkan ${ }^{\mathrm{a}, *}$, Michela Chiumenti ${ }^{\mathrm{b}}$, Sébastien Massart ${ }^{\mathrm{c}}$, Kamil Sarpkaya ${ }^{\mathrm{d}}$, Serpil Karadağ ${ }^{\mathrm{d}}$, \\ Angelantonio Minafra ${ }^{\mathrm{b}}$ \\ ${ }^{a}$ Dep. of Plant Protection, Faculty of Agriculture, University of Sütçü Imam, Kahramanmaras 46060, Turkey \\ ${ }^{\mathrm{b}}$ Institute for Sustainable Plant Protection, CNR, Via Amendola 122/D, Bari 70126, Italy \\ ${ }^{\mathrm{c}}$ Plant Pathology Laboratory, TERRA-Gembloux Agro-Bio Tech, University of Liège, Passage des Déportés, 2, 5030 Gembloux, Belgium \\ ${ }^{\mathrm{d}}$ Pistachio Research Institute, University Blvd., 136/C 27060 Sahinbey, Gaziantep, Turkey
}

\section{A R T I C L E I N F O}

\section{Keywords:}

Emaravirus

High throughput sequencing

Pistachio

\begin{abstract}
A B S T R A C T
High throughput sequencing was performed on total pooled RNA from six Turkish trees of Pistacia showing different viral symptoms. The analysis produced some contigs showing similarity with RNAs of emaraviruses. Seven distinct negative-sense, single-stranded RNAs were identified as belonging to a new putative virus infecting pistachio. The amino acid sequence identity compared to homologs in the genus Emaravirus ranged from $71 \%$ for the replicase gene on RNA1, to $36 \%$ for the putative RNA7 gene product. All the RNA molecules were verified in a pistachio plant by RT-PCR and conventional sequencing. Although the analysed plants showed a range of symptoms, it was not possible to univocally associate the virus with a peculiar one. The possible virus transmission by mite vector needs to be demonstrated by a survey, to observe spread and potential effect on yield in the growing areas of the crop.
\end{abstract}

Pistachio (Pistacia spp.) is an important crop worldwide, with a global production of more than 1 million tons (FAOstat, 2016). In Turkey, that is the third largest producer in the world after USA and Iran, plantations are mainly located in the Southeast Anatolia region under semi-arid conditions. Most of the trees from varietal collections, grafted on $P$. khinjuk and P. terebinthus at Kahramanmaras Sutcu Imam University, as well as from commercial orchards in the Eastern Mediterranean, showed virus-like symptoms, i.e. diffused chlorotic spots around secondary veins, mosaic pattern, leaf malformation, shoestringed young twigs and reduced growth. The most important effect of this variable symptom expression derives as small nut formation and reduced yield.

Very few reports described the presence of viruses or viroids affecting Pistacia spp. A rosette disease was described in the former USSR (Kreutzberg, 1940) while only recently the ubiquitous Hop stunt viroid was found in Tunisia (Elleuch et al., 2013) and in Turkey (Balsak et al., 2017). Consistent association of phytoplasma with witches broom and yellows diseases was also reported in Iran (Ghayeb Zamharir et al., 2011; Ghayeb Zamharir, 2018). The application of high-throughput sequencing (HTS) to detect viruses in plant samples (Massart et al., 2014) has been a boost for the association of viruses to diseased accessions or even to symptomless plants, also in pistachio. Al Rwahnih et al. (2018) described a new putative ampelovirus (Pistachio ampelovirus A) and a pistachio variant of a viroid (Citrus bark cracking viroid-pistachio), that turned to be both graft-transmissible, and a caulimo-like virus was also recently identified (Diaz-Lara et al., 2017).

To shed further light on this poorly explored field of pistachio-infecting viruses, a HTS analysis of several Pistacia samples from Turkey was done and this brought to the de novo discovery of a new putative emaravirus. Emaraviruses have enveloped virions whose genome is constituted of four to eight negative-sense, single-stranded RNAs (Mielke-Ehret and Mühlbach, 2012). Each segment of the genome encodes a single protein translated from the complementary strand. Most of the members of the genus Emaravirus (family Fimoviridae in the order Bunyavirales; Elbeaino et al., 2018) have been recently discovered or deeply characterized by HTS technique (Di Bello et al., 2015; Elbeaino et al., 2014, 2015; Hassan et al., 2017; Lu et al., 2015; Tatineni et al., 2014; Zheng et al., 2017).

Leaf samples from 6 pistachio accessions (5, 23, 29, 48, 70 and F6), showing different symptoms, were collected in Kahramanmaras and Mersin (Turkey) in June 2017. All the sources belong to the species Pistacia vera L., but sample 5 that was from Pistacia khinjuk. This plant material was immediately freeze-dried and the extraction of total RNA was performed from $250 \mathrm{mg}$ of dried tissues through silica particles capture (Foissac et al., 2001) and further purified by a $3 \mathrm{M} \mathrm{LiCl}$ precipitation. Total RNA was then digested with RNAse free-DNAse I

\footnotetext{
* Corresponding author.

E-mail address: nbuzkan@ksu.edu.tr (N. Buzkan).
} 
Table 1

Assembled contigs and related RNA segments of the Pistacia emaravirus (PiVB) genome. Query coverage and identity are related to the best match in BlastX.

\begin{tabular}{|c|c|c|c|c|c|c|}
\hline RNA genomic segment & Contig number & Size (nt) & Best match in BlastX (accession nr) & Query coverage (\%) & Sequence identity (\%) & Accession numbers (NCBI, GenBank) \\
\hline RNA1 & 1107 & 7027 & RRV (AXI82304.1) & 98 & 71 & MH727572 \\
\hline \multirow{2}{*}{ RNA2 } & $1129^{\mathrm{a}}$ & 2244 & PSMV2 (YP_009268865.1) & 85 & 57 & MH727573 \\
\hline & 900 & 2244 & PSMV2 (YP_009268865.1) & 85 & 57 & \\
\hline \multirow[t]{4}{*}{ RNA3 } & $2799^{\mathrm{a}}$ & 1525 & PSMV2 (ANQ90739.1) & 59 & 62 & MH727574 \\
\hline & 4077 & 1126 & PSMV2 (ANQ90740.1) & 65 & 66 & \\
\hline & 3733 & 1184 & PSMV2 (ALU34071.1) & 70 & 65 & \\
\hline & 1107 & 1371 & PSMV2 (ALU34071.1) & 61 & 65 & \\
\hline \multirow[t]{2}{*}{ RNA4 } & $2725^{\mathrm{a}}$ & 1550 & FMV (AEI98679.1) & 69 & 73 & MH727575 \\
\hline & 2128 & 1550 & FMV (AEI98679.1) & 67 & 73 & \\
\hline \multirow[t]{4}{*}{ RNA5 } & 2178 & 1713 & PSMV1 (ANQ90718.1) & 84 & 36 & \\
\hline & $1578^{\mathrm{a}}$ & 1711 & PSMV1 (ANQ90718.1) & 84 & 36 & MH727577 \\
\hline & $1801^{\mathrm{a}}$ & 1716 & PSMV2 (YP_009268861.1) & 84 & 36 & MH727576 \\
\hline & 2476 & 1663 & RRV (AXI82316.1) & 86 & 37 & \\
\hline \multirow[t]{3}{*}{ RNA6 } & $3532^{\mathrm{a}}$ & 1340 & BLMaV (AQX45477.1) & 43 & 39 & MH727578 \\
\hline & 4799 & 1019 & BLMaV (AQX45477.1) & 57 & 40 & \\
\hline & 2549 & 1356 & BLMaV (AQX45477.1) & 39 & 40 & \\
\hline \multirow[t]{3}{*}{ RNA7 } & $1621^{\mathrm{a}}$ & 1709 & RRV (AXI82319.1) & 85 & 36 & MH727579 \\
\hline & 3362 & 1257 & RRV (YP_009380549.1) & 79 & 40 & \\
\hline & 4147 & 1289 & RRV (YP_009380549.1) & 86 & 36 & \\
\hline
\end{tabular}

\footnotetext{
a Reference contigs, full or near full-length, that have been deposited to GenBank.
}

(Ambion) and a pool of the six samples was processed at the sequencing facility of Liège University (GIGA, Belgium). Ribosomal RNA was removed using a RiboMinus Plant Kit for RNA-Seq (ThermoFisher Scientific, USA). A total RNA library was then prepared using a simplified protocol (no enrichment in poly-A RNA) with a TrueSeq Stranded mRNA kit (Illumina, USA). The sequencing was carried out on Nextseq 500 sequencing machine with $2 \times 150$ nt sequencing reads.

After primary quality check, the obtained reads were paired, merged and the duplicates eliminated using Geneious software (Biomatters, New Zealand). They were further assembled in contigs by AS SPAdes software embedded in Geneious (Bankevich et al., 2012). Annotation of contigs was performed using either BlastN or BlastX algorithm based on NCBI nt and viral protein databases, respectively (Altschul et al., 1997).

Contigs with homologies to emaravirus RNAs (Table 1) were partitioned according to the similarity with homologous protein hits found in BlastX. Then, contigs putatively assigned to each specific RNA molecule were aligned by Clustal Omega (Sievers et al., 2011) as nucleotide complementary-sense coding sequences (with ORFs in positive sense checked by DNA Strider 1.4f6) (Marck, 1988). Polypeptide inferred from the RNA2 ORF, described as a glycoprotein precursor and known to undergo to protease activity, was also screened for potential cleavage sites with SignalP 3.0 (Emanuelsson et al., 2007). A conserved domain search was done by the NCBI CD Search tool (Marchler-Bauer et al., 2015). Finally, two complete gene products (from RNA1 and RNA3) were analysed for their phylogenetic relationships with homologous proteins of related emaraviruses and tospoviruses and the NeighbourJoining trees were calculated and bootstrapped by MEGA 4.0 (Tamura et al., 2011).

To confirm the presence of each in silico-identified RNA, specific sets of primers were designed on consensus sequences (where contig alignments presented conserved nucleotide stretches) (Suppl. Table 1). RNA extracts from the 6 original plants were reverse transcribed, using random primers, by Superscript IV (ThermoScientific) and amplified by Wonder Taq DNA polymerase (Euroclone, Italy). Obtained amplicons were directly sequenced in both directions (Macrogen, The Netherlands) and compared with the original contig sequences.

The obtained reads (total of 5,259,903 per end) were assembled into 79,645 contigs (mean length $386 \mathrm{bp}$, minimum length $86 \mathrm{bp}$, maximum length 23,680). The Blast analysis identified several larger contigs sharing similarity to emaraviruses RNAs (Table 1). The selected contigs were sorted by specific genomic RNA segments based on the homology retrieved by Blast. This was the case of RNA1 to RNA6, where a homologous counterpart was found in the database. The reads that were attributed by mapping to the emaravirus genome segments consisted in $0.79 \%$ out of total (Suppl. Table 2). Two large contigs (about 4000 bases) were also assembled from the library, which covered the $3^{\prime}$ end region of a putatively new rhabdovirus. In the focus of the present work, these latter contigs were not used for further elaborations.

The number of genomic RNAs is variable in the emaravirus species (from 4 to 8) (Mielke-Ehret and Mühlbach, 2012; Tatineni et al., 2014) and an intrinsic genetic variability among the RNAs bearing the same function is also an evidence (Tatineni et al., 2014; Lu et al., 2015; Stewart, 2016). Therefore, it was not unexpected the finding that in a same pistachio accession (plant 5): (i) two divergent consensus sequences leading to variants of RNA3 were present; (ii) at least two variants of RNA5 were identified as distinct contigs (RNA5a and RNA5b); (iii) a putative RNA 7 was described, sharing all the requisites for a correct attribution as an emaravirus genomic segment.

Based on the full RNA sequences obtained, an in depth bioinformatic analysis was carried out. All the described segments possess the $13 \mathrm{nt}$ of the bunyavirus RNA consensus, forming a panhandle structure at both $5^{\prime}$ and $3^{\prime}$ termini (...GGAGUUCACUACU- $3^{\prime}$ ), fully reconstructed at the $3^{\prime}$ genomic termination. The matching counterpart at $5^{\prime}$ end (with the two mismatches at position 8 and 9) was fully reconstructed, from the contig assembly, only for the RNA4 and RNA6. For the other 5' RNA untranslated regions, 2 (for RNA3) to 12 (for RNA7) nucleotides out of the 13 positions of this structure were identified in the consensus. The alignments of the $5^{\prime}$ and $3^{\prime}$ terminal regions of the RNA1 to RNA5 with the homolog segments of some related emaraviruses are shown in Suppl. Fig. 2.

All the non-redundant (NR) reads were also mapped on the full RNA consensus sequences (CLC Genomic workbench v5.5) as a further assessment. All the RNAs were covered by NR reads with a coverage ranging from 111.85x (RNA2) to 574.07x (RNA4). Pairwise identity of aligned reads to the consensus sequences showed an intraspecific variability above $95 \%$, up to $97.7 \%$ (RNA7) except for RNA5a, whose percentage pairwise identity is of $91.6 \%$ (Suppl. Table 2).

RNA1 was reconstructed as a single contig and consists of 7,027-ntlong. Its $6900 \mathrm{nt}$ coding sequence is predicted to synthesize a $2686 \mathrm{kDa}$ protein ( $p 1)$. It functions as an RdRp and contains the described conserved motifs (pre-A to E) inside the bunyavirus replicases (Elbeaino et al., 2013; Reguera et al., 2010), from aa 1046 to 1321. At the Nterminal part, $p 1$ contains the conserved motifs involved in the capsnatching mechanism for the mRNA priming (RH...PD...DxK) (Laney et al., 2011; Walia and Falk, 2012; Zheng et al., 2017). 
RNA2 is 2,244 nt in length and the coding sequence of $1923 \mathrm{nt}$ produces a polypeptide of $73.5 \mathrm{kDa}$ in size. This protein is considered the glycoprotein precursor used in virion assembly. It contains the

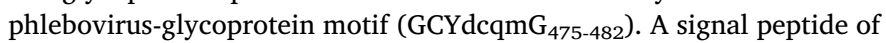
22 aa is possibly cleaved at $\mathrm{N}$-terminal region $\left(\ldots \mathrm{VYT}_{22} / \mathrm{R}_{23} \mathrm{~L} \ldots\right)$, while a predicted cleavage site at the sequence $\mathrm{AKA}_{189}-\mathrm{D}_{190} \mathrm{D}$ could produce two mature proteins (named $G c$ and $G n$ ), as verified in other emaraviruses (Mielke-Ehret and Mühlbach, 2012).

The RNA3 polypeptide product should represent the nucleocapsid protein. As in High Plains wheat mosaic virus (Tatineni et al., 2014; Stewart, 2016), we found a significant polymorphism in consensus sequences leading to two distinct contigs (first contig with a complete length of $1525 \mathrm{nt}$, coding for $305 \mathrm{aa}$, and the second contig, which has a partial untranslated region but a similar ORF coding for 304 aa) which share with each other $78.6 \%$ of aa identity. A p3 protein of $34.3 \mathrm{kDa}$ could be translated by both RNA3 segments, sharing the conserved emaravirus nucleocapsid motifs (NVLSFNK $134-140$, NRLA $_{183-186}$ and GYEF $_{\text {204-207) }}$ (Elbeaino et al., 2009; Hassan et al., 2017; Zheng et al., 2017).

RNA4 is a 1,550-nt-long segment coding for a $40.7 \mathrm{kDa}$ polypeptide. The $p 4$ protein shows a remarkable homology with FMV and PPSMV-2 p4 (73 and 67\% identity, respectively) and is recognized as belonging to Emaravirus_P4 superfamily (pfam16505), thus sharing the function of a movement protein. This function was experimentally demonstrated for RLBV (Yu et al., 2013) and FMV (Ishikawa et al., 2013).

Similar to RNA3, a variability was observed for RNA5. Among the contigs reaching an amino acid identity of about $36 \%$ with other emaraviruses RNA5, two of them with a near-complete structure of panhandle terminations and whole untranslated regions, shared each other $56.6 \%$ of identity (Suppl. Table 3). Another contig, named RNA5a, is $1716 \mathrm{nt}$ long with a coding sequence of $1449 \mathrm{nt}$ and a predicted protein of $56.6 \mathrm{kDa}$. The other, named RNA5b, with a length of $1711 \mathrm{nt}$, bears a coding sequence of $1452 \mathrm{nt}$ for a protein size of $57.3 \mathrm{kDa}$. These hypothetical proteins, likewise the other emaravirus homologs, do not have yet any known function. An exception is represented by the p5 of RRV (Di Bello et al., 2015), in which the presence of a RNA binding domain and glycosilation sites can figure out a role in nucleic acid interaction.

RNA6 has an ORF of $723 \mathrm{nt}$ in a total sequenced length of $1340 \mathrm{nt}$ included the fully conserved terminations. Amino acid identity of its protein (with a molecular weight of $27.8 \mathrm{kDa}$ ) ranges from $39 \%$ with BLMaV p6, 29\% with FMV p6, up to $24 \%$ with those of PPSMV-1 and -2 . Again, no function could be ascribed to this polypeptide.

As already known for other emaravirus genomes discovered by HTS (mainly RRV and HPWMoV), some virus-specific genomic segments (other than the canonical RNA 1 to 4) can produce HTS-derived contig sequences with all the requisites (termini structure, negative-sense ORF, dimension of coding sequence) to be attributed as viral sequences. In RRV (Di Bello et al., 2015), proteins translated from RNA5 and RNA7 have an aminoacidic identity of 73\%. In such a way, we analysed a RNA segment, with a size of $1709 \mathrm{nt}$ and a coding sequence of $1515 \mathrm{nt}$. This segment was putatively named RNA7 and its protein ( $p 7)$ shares a discrete homology with $p 5$ of PPSMV-1 and -2 (identity 36\%) and, not surprisingly, also with $p 5$ and $p 7$ of RRV (identity $37 \%$ ). The analysis of the same $p 7$ versus the contigs assimilated to RNA5 in pistachio produces identity values of 48 and $57 \%$, respectively (Suppl. Table 3). While two in-frame ATG starting codons (positions versus15-17 and 87-89) are in balance as the authentic protein translation initiation of RNA7, none of them anyway responds to the Lutcke et al. (1987) consensus for plant mRNA translation. It is noteworthy that the BlastX output of this sequence, and not those from the related homolog proteins, recognizes some similarity with a conserved domain of the NBD94 superfamily. This conserved domain, sharing a nucleotide binding behaviour, is reported to be embedded in reticulocyte-binding proteins of Plasmodium spp. (Gruber et al., 2010) (Suppl. Fig. 1A). When this $p 7$ protein stretch from the pistachio emaravirus was aligned against the $p 7$ sequences of RRV, $40 \%$ of these residues were still preserving a remarkable conservation (Suppl. Fig. 1B). The same feature is not verified when HPWMoV $p 7$ were similarly aligned (not shown).

Lu et al. (2015), investigating the role for p6 and p7 in RLBV, assessed that these proteins increased the virus pathogenicity and could act as silencing suppressors. This function in silencing suppression activity was indeed clearly demonstrated in agroinfiltration experiments for p7 and p8 of HPWMoV (Gupta et al., 2018).

The RT-PCR reactions, performed to verify the presence of the contigs in plant extracts, were carried out on the 6 pistachio samples of the sequenced pool. Positive PCR products of RNA4 were detected only from 3 accessions (5, 48 and 70); the amplicon of RNA3 was found in accessions 5 and 70 . All the other primer sets failed to amplify on the other pistachio sources (not shown). On RNA extracts of plant 5, all the tested segment-specific set of primers (Suppl. Table 1) successfully amplified a true-size expected band (not shown). Sequences from the amplicons were pairwise aligned with the related consensus sequence from the original contigs and a certain variability was observed in the matching percentages of the comparisons. As an example, amplicons specific for each one of the two RNA3 variants ranged from a $24.6 \%$ divergence when compared to the heterologous variant, to a $98 \% \mathrm{nu}-$ cleotide identity with the homologous one. Amplicons from RNA4, RNA6 and RNA7 had an identity of 94\%, $91 \%$ and $94.6 \%$, respectively, with the corresponding contigs obtained by HTS. An extended analysis of intra-isolate genetic variability along the genomic components of the newly described virus in pistachio was out of the scope of the present work, while a confirmation for the presence of such a different array of RNAs was the minimal due assessment (Massart et al., 2017). Because of the presence of all the 7 targeted RNA sequences was verified at least in a single plant (accession 5) of the HTS-analysed pool of pistachio extracts, this consistent array of genomic segments can lead to a definition of the putative new virus as Pistacia virus B (PiVB).

The phylogenetic analysis run for the RdRp and nucleocapsid proteins (Fig. 1A and C) confirms the established picture described in the last reports about new emaraviruses (Hassan et al., 2017; Zheng et al., 2017). For both the trees, three structured subclades among the species belonging to the genus Emaravirus have a clear-cut support. A distinct speciation line can be observed, anyway, for PiVB outside the subclade which contains RRV, BLMaV, FMV and PPSMV-2, whereas HPWMoV and RLBV have a separate clade position, like in Tatineni et al. (2014). The identity matrix tables associated to these elaborations (Fig. 1B and D) on representative protein references are specular to the detected distances. The higher variability is shown toward the tospoviruses, either for RdRp and $p 3$ (17.4-20.3\% and $12.0-15.9 \%$ of conservation, respectively). The conservation of amino acidic residues, inside the specified subclade and for the most conserved replicase gene, ranges from 67.7 (PiVB with BLMaV) to 70.8\% (PiVB with RRV). Notably, also the second identified PiVB RNA3 variant performs with the same values in the $p 3$ comparisons (not shown), as it happens for the HPWMoV RNA3 variants.

Reason and amount of the intrinsic variability among RNAs need to be better investigated in a future, when a large amount of PiVB genomic sequences from diverse samples could be compared. The species demarcation threshold inside the genus Emaravirus has been recently set at more than $25 \%$ of amino acid divergence for relevant gene products (Elbeaino et al., 2018). The evidence of some RNA segments duplication in certain species (and even not in all the infected accessions), is an indication of the co-infection of different molecular variants of the same virus. In raspberry leaf blotch virus, the two RNA 8 segments share a $90 \%$ identical coding sequence (as amino acids), while P3-A and P3-B of HPWMoV show $11 \%$ within-isolate and $17.4 \%$ inter-isolate amino acid sequence divergences. In such multipartite genomes, it is also conceivable a different selective pressure exerted on RNAs. Among fig mosaic virus isolates, Walia et al. (2014) described a 5-times higher genetic variation (as nucleotide distance) in RNA1 and RNA2 than in RNA 3 and 4. This variable selection can explain the range of variation 
A
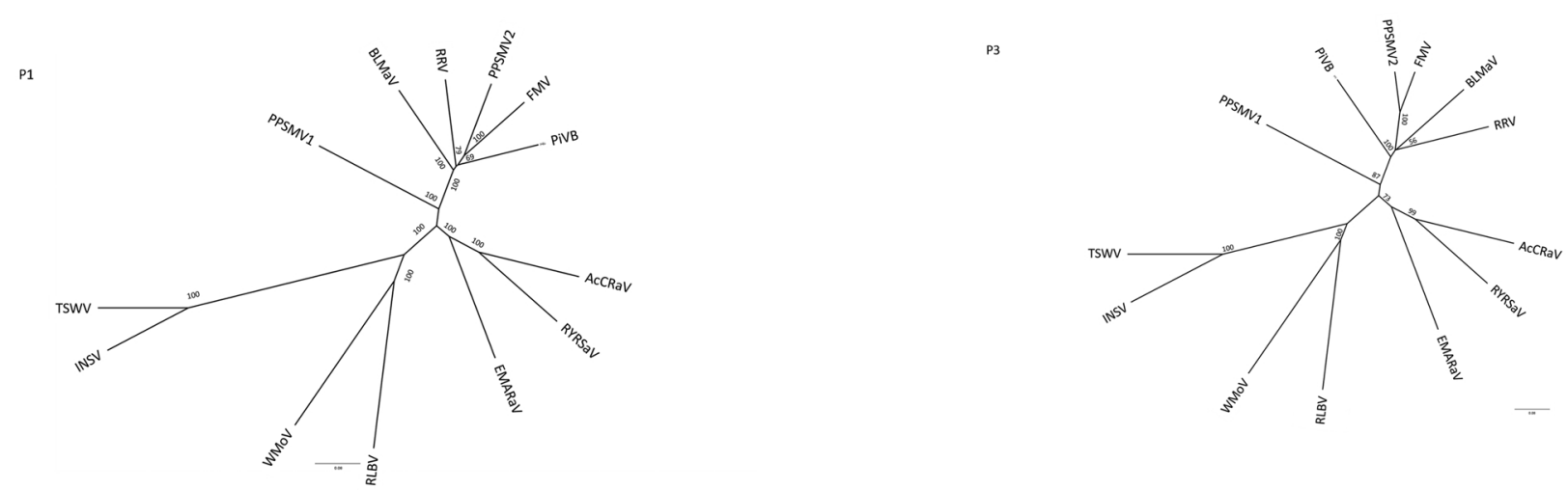

C

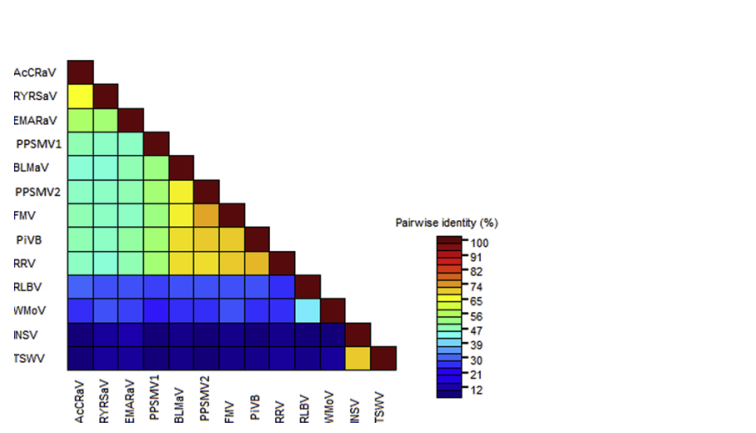

B

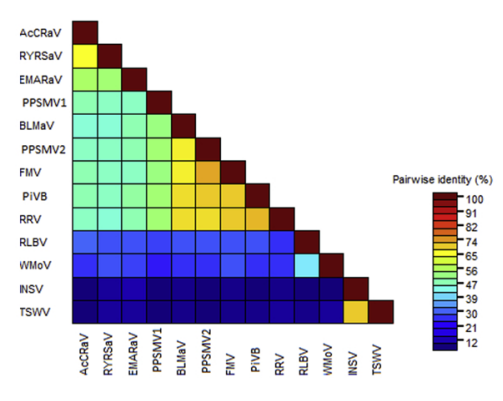

Fig. 1. Phylogeny and aminoacid identity matrix comparison (\%) for PiVB $p 1$ (A and B) and $p 3$ (C and D) among emaraviruses and tospoviruses. Neighbor-joining tree with reproduced bootstrap replicates indicated at nodes.

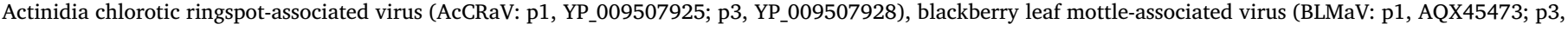

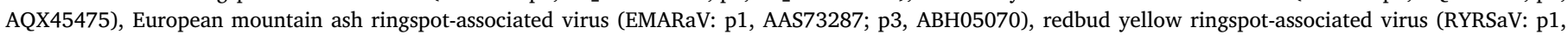

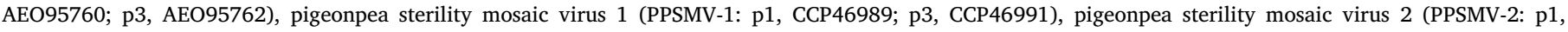

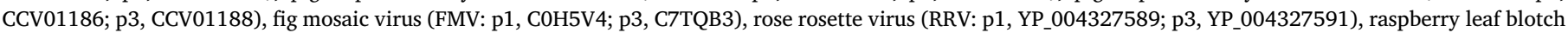

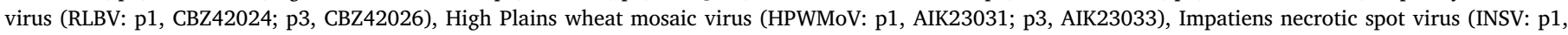
NP_619710; p3, NP_619709), tomato spotted wilt virus (TSWV: p1, BAA00955; p3, NP_049361).

found among sequenced amplicons in PiVB (see above). A further consequence of the inter-isolate variability could be the absence of amplification due to mismatches of some primer sets in our pistachio accessions.

Finally, the reassortment of RNA segments and their exchange among strains has been claimed in FMV and PPSMV2 (Walia et al., 2014; Patil et al., 2017). The possibility that also PiVB infection is vehiculated by eryophid mites clues for a super-infection of different strains in the same perennial and clonally-propagated plants. Even in PiVB the presence of more genomic segments cannot be excluded, although they have not been detected by the HTS of the samples. From a merely biological point of view, the role of the additional proteins ( $p 5$ to $p 7$ ), out of the 'core' activity of $p 1$ to $p 4$ associated to virus replication and tissue tropism, can be helpful for many accessory functions (vector transmission, suppression of gene silencing, host range determination, etc.) (Tatineni et al., 2014; Gupta et al., 2018). The preliminary piece of evidence of a conserved, non-virus derived domain embedded in RNA7 (NBD94), most likely playing a nucleic acid interaction activity and not described so far in other emaraviruses, is a further suggestion for a modular evolution in this genus of plant viruses (Di Bello et al., 2015; Patil et al., 2017). The correct coding frame conservation in all the RNA segments, together with the sequencing method used (paired ends $150 \mathrm{nt}$ ), excluded possible artificial chimeric assemblies of the PiVB. Moreover, natural recombination events have been described as rare or occurring at a low rate among negative-sense RNA viruses (Chare et al., 2003).

The simple description of the genomic features of a newly identified plant virus, solely through HTS technique, does not cover the questions pathway for assessing correctly a potential phytopathological problem
(Olmos et al., 2018). At first, the detection of the virus in only $50 \%$ of the selected pistachio plants and the variability of observed symptoms in the bunch of analysed samples do not allow the association of this viral species with any distinct symptom. The presence of other viruses or virus-like agents cannot be excluded as well as their eventual role in disease(s). The number of virus genera picked up by the HTS study of Al Rwahnih et al. (2018) in California, as affecting pistachio, suggests that the list of viral pathogens is going to increase for this crop.

A wider survey in the pistachio-growing areas and germplasm is also envisaged to reveal the incidence of PiVB and its association to any alteration.

\section{Funding}

The networking activities were supported by the COST Action grant number FA1407.

\section{Declaration of interest}

None.

\section{Acknowledgments}

Authors wish to thank Agah Aktan at Pistachio Research Station (Turkey) for his technical support and Assist. Prof. Yusuf Nikpeyma at Horticulture Department (Agriculture Faculty, Sütçü Imam University) for supplying plant materials. 


\section{Appendix A. Supplementary data}

Supplementary material related to this article can be found, in the online version, at https://doi.org/10.1016/j.virusres.2019.01.012.

\section{References}

Al Rwahnih, M., Rowhani, A., Westrick, N., Stevens, K., Diaz-Lara, A., Trouillas, F.P., Preece, J., Kallsen, C., Farrar, K., Golino, D., 2018. Discovery of viruses and virus-like pathogens in pistachio using high-throughput sequencing. Plant Dis. 102, 1419-1425. https://doi.org/10.1094/PDIS-12-17-1988-RE.

Altschul, S.F., Madden, T.L., Schaffer, A.A., Zhang, J., Zhang, Z., Miller, W., Lipman, D.J., 1997. Gapped BLAST and PSIBLAST: a new generation of protein database search programs. Nucleic Acids Res. 25, 3389-3402.

Balsak, S.C., Buzkan, N., Ay, M.Z., Gürbüz, M., 2017. Occurrence of Hop stunt viroid (HSVD) in Turkish pistachio trees. Phytopathol. Mediterr. 56, 376.

Bankevich, A., Nurk, S., Antipov, D., Gurevich, A., Dvorkin, M., Kulikov, A.S., Lesin, V., Nikolenko, S., Pham, S., Prjibelski, A., Pyshkin, A., Sirotkin, A., Vyahhi, N., Tesler, G., Alekseyev, M.A., Pevzner, P.A., 2012. SPAdes: a new genome assembly algorithm and its applications to single-cell sequencing. J. Comput. Biol. 19, 455-477.

Chare, E.R., Gould, E.A., Holmes, E.C., 2003. Phylogenetic analysis reveals a low rate of homologous recombination in negative-sense RNA viruses. J. Gen. Virol. 84, 2691-2703.

Di Bello, P.L., Ho, T., Tzanetakis, I.E., 2015. The evolution of emaraviruses is becoming more complex: seven segments identified in the causal agent of Rose rosette disease. Virus Res. 210, 241-244.

Diaz-Lara, A., Stevens, K., Westrick, N., Golino, D.A., Al Rwahnih, M., 2017. Identification of a caulimo-like virus in pistachio via high-throughput sequencing (Abstr.). Phytopathology 103, S5.1. https://doi.org/10.1094/PHYTO-107-12-S5.1.

Elbeaino, T., Digiaro, M., Martelli, G.P., 2009. Complete nucleotide sequence of four RNA segments of Fig mosaic virus. Arch. Virol. 154, 1719-1727.

Elbeaino, T., Whitfield, A., Sharma, M., Digiaro, M., 2013. Emaravirus-specific degenerate PCR primers allowed the identification of partial RNA-dependent RNA polymerase sequences of Maize red stripe virus and Pigeonpea sterility mosaic virus. J. Virol. Methods 188, 37-40.

Elbeaino, T., Digiaro, M., Uppala, M., Sudini, H., 2014. Deep sequencing of Pigeonpea sterility mosaic virus discloses five RNA segments related to emaraviruses. Virus Res. $188,27-31$.

Elbeaino, T., Digiaro, M., Uppala, M., Sudini, H., 2015. Deep sequencing of dsRNAs recovered from mosaic-diseased pigeonpea reveals the presence of a novel emaravirus: pigeonpea sterility mosaic virus 2. Arch. Virol. 160, 2019-2029.

Elbeaino, T., Digiaro, M., Mielke-Ehret, N., Muehlbach, H., Martelli, G.P., ICTV Report Consortium, 2018. ICTV virus taxonomy profile: fimoviridae. J. Gen. Virol. 99, 1478-1479.

Elleuch, A., Hamdi, I., Ellouze, O., Ghrab, M., Fkahfakh, H., Drira, N., 2013. Pistachio (Pistacia vera L.) is a new natural host of Hop stunt viroid. Virus Genes 47, 330-337.

Emanuelsson, O., Brunak, S., von Heijne, G., Nielsen, H., 2007. Locating proteins in the cell using TargetP, SignalP and related tools. Nat. Protoc. 2, 953-971.

FAOstat, 2016. FAO Statistics. (Accessed on 17 September 2018). http://www.fao.org/ faostat/.

Foissac, X., Svanella-Dumas, L., Dulucq, M.J., Candresse, T., Gentit, P., 2001. Polyvalent detection of fruit tree tricho, capillo and foveavirus by nested RT-PCR using degenerated and inosine containing primers (DOP RT-PCR). Acta Hortic. 550, 37-44.

Ghayeb Zamharir, M., 2018. Molecular study of phytoplasmas associated with pistachio yellows in Iran. J. Phytopathol. 166, 161-166.

Ghayeb Zamharir, M., Mirabolfathi, M., 2011. Association of a phytoplasma with pistachio witches' broom disease in Iran. J. Phytopathol. 159, 60-62.

Gruber, A., Manimekalai, M.S.S., Balakrishna, A.M., Hunke, C., Jeyakanthan, J., et al., 2010. Structural determination of functional units of the nucleotide binding domain (NBD94) of the reticulocyte binding protein Py235 of plasmodium yoelii. PLoS One 5 (2), e9146. https://doi.org/10.1371/journal.pone.0009146.

Gupta, A.K., Hein, G.L., Graybosch, R.A., Tatineni, S., 2018. Octapartite negative-sense
RNA genome of High Plains wheat mosaic virus encodes two suppressors of RNA silencing. Virology 518, 152-162.

Hassan, M., Di Bello, P.L., Keller, K.E., Martin, R.R., Sabanadzovic, S., Tzanetakis, I.E., 2017. A new, widespread emaravirus discovered in blackberry. Virus Res. 235, 1-5. Ishikawa, K., Maejima, K., Komatsu, K., Netsu, O., Keima, T., Shiraishi, T., Okano, Y. Hashimoto, M., Yamaji, Y., Namba, S., 2013. Fig mosaic emaravirus p4 protein is involved in cell-to-cell movement. J. Gen. Virol. 94, 682-686.

Kreutzberg, V.E., 1940. A new virus of Pistacia vera L. Proc. Acad. Sci. USSR, Geochem. Sect. 27, 614-617.

Laney, A.G., Keller, K.E., Martin, R.R., Tzanetakis, I.E., 2011. A discovery 70 years in the making: characterization of the rose rosette virus. J. Gen. Virol. 92, 1727-1732.

Lu, Y., McGavin, W., Cock, P.J., Schnettler, E., Yan, F., Chen, J., MacFarlane, S., 2015. Newly identified RNAs of raspberry leaf blotch virus encoding a related group of proteins. J. Gen. Virol. 96, 3432-3439.

Lutcke, H.A., Chow, K.C., Mickel, F.S., Moss, K.A., Kern, H.F., Scheele, G.A., 1987. Selection of AUG initiation codons differs in plants and animals. EMBO J. 6, 43-48.

Marchler-Bauer, A., et al., 2015. CDD: NCBI's conserved domain database. Nucleic Acids Res. 43, 222-226.

Marck, C., 1988. DNA Strider: a "C" program for the fast analysis of DNA and protein sequences on the Apple Macintosh family computer. Nucleic Acids Res. 16, 1829-1836.

Massart, S., Olmos, A., Jijakli, H., Candresse, T., 2014. Current impact and future directions of high throughput sequencing in plant virus diagnostics. Virus Res. 188, 90-96.

Massart, S., Candresse, T., Gil, J., Lacomme, C., Predajna, L., Ravnikar, M., Reynard, J.-S., Rumbou, A., Saldarelli, P., Škoric, D., Vainio, E.J., Valkonen, J.P.T., Vanderschuren, H., Varveri, C., Wetzel, T., 2017. A framework for the evaluation of biosecurity, commercial, regulatory, and scientific impacts of plant viruses and viroids identified by NGS technologies. Front. Microbiol. 8, 45. https://doi.org/10.3389/fmicb.2017. 00045 .

Mielke-Ehret, N., Mühlbach, H.P., 2012. Emaravirus: a novel genus of multipartite, negative strand RNA plant viruses. Viruses 4, 1515-1536.

Olmos, A., et al., 2018. High-throughput sequencing technologies for plant pest diagnosis: challenges and opportunities. Bull. OEPP/EPPO Bull. 48, 219-224.

Patil, B.L., Dangwal, M., Mishra, R., 2017. Variability of emaravirus species associated with sterility mosaic disease of Pigeonpea in India provides evidence of segment reassortment. Viruses 9, 183. https://doi.org/10.3390/v9070183.

Reguera, J., Weber, F., Cusack, S., 2010. Bunyaviridae RNA polymerases (Lprotein) have an N-terminal, influenza-like endonuclease domain, essential for viral cap-dependent transcription. PLoS Pathol. 6, 8871-8887.

Sievers, F., Wilm, A., Dineen, D., Gibson, T.J., Karplus, K., Li, W., Lopez, R., McWilliam, H., Remmert, M., Söding, J., Thompson, J.D., Higgins, D.G., 2011. Fast, scalable generation of high-quality protein multiple sequence alignments using Clusta Omega. Mol. Syst. Biol. 7 (1), 539.

Stewart, L.R., 2016. Sequence diversity of wheat mosaic virus isolates. Virus Res. 213, 299-303.

Tamura, K., Peterson, D., Peterson, N., Stecher, G., Nei, M., Kumar, S., 2011. MEGA5: molecular evolutionary genetics analysis using maximum likelihood, evolutionary distance, and maximum parsimony methods. Mol. Biol. Evol. 28, 2731-2739.

Tatineni, S., McMechan, A.J., Wosula, E.N., Wegulo, S.N., Graybosch, R.A., French, R., Hein, G.L., 2014. An eriophyid mite-transmitted plant virus contains eight genomic RNA segments with unusual heterogeneity in the nucleocapsid protein. J. Virol. 88 (11) 834-11 845.

Walia, J.J., Falk, B.W., 2012. Fig mosaic virus mRNAs show generation by capsnatching. Virology 426, 162-166.

Walia, J.J., Willemsen, A., Elci, E., Caglayan, K., Falk, B.W., Rubio, L., 2014. Genetic variation and possible mechanisms driving the evolution of worldwide Fig mosaic virus isolates. Phytopathology 104, 108-114.

Yu, C., Karlin, D.G., Lu, Y., Wright, K., Chen, J., MacFarlane, S., 2013. Experimental and bioinformatic evidence that raspberry leaf blotch Emaravirus P4 is a movement protein of the 30K superfamily. J. Gen. Virol. 94, 2117-2128.

Zheng, Y., Navarro, B., Wang, G., Wang, Y., Yang, Z., Xu, W., Zhu, C., Wang, L., Di Serio, F., Hong, N., 2017. Actinidia chlorotic ringspot-associated virus: a novel emaravirus infecting kiwifruit plants. Mol. Plant Path. 18, 569-581. 